National Emergency Airway Management Course. Presented by Drs. Ron Walls, Michael Murphy, Robert Schneider and Robert Luten. 1999. US\$895 (CAEP members: US\$625).

$\mathrm{I}^{\mathrm{r}}$ reviewed the National Emergency Airway Management Course (NEAMC) for CAEP in October 1999. This course is an advanced program intended for emergency physicians who want to upgrade their airway management skills to the highest level.

The NEAMC's founding faculty members are Canadians Ron Walls and Michael Murphy, and Americans Robert Schneider and Robert Luten; however, NEAMC faculty includes several other internationally recognized adult and pediatric emergency physicians.

The intensive 2-day program runs from 0700 to 1830 . All aspects of emergency department (ED) airway management are covered in lectures and workshops, and an excellent course manual is provided. Rapid sequence intubation, crash intubation, the difficult airway, the failed airway, and airway management in trauma were covered, as well as pediatric and medical emergencies. The pediatric content was better than any course I have attended.

Drugs used to facilitate intubation were also discussed. Of interest, the largely US faculty seemed unfamiliar with midazolam, and there was little discussion of alternatives such as propofol, although they were covered in the manual.

There were challenging skill stations for bag-valve-mask ventilation, laryn- goscopy, mechanical ventilation, BiPAP, pediatric airways, surgical airways, advanced airway tools and fibreoptics. Two "code" stations addressed basic and complex airway problems. All scenarios were presented, and each candidate had an opportunity to try the stations.

The faculty was excellent and used up-to-date adult learning principles. In a relaxed atmosphere, participants were individually challenged and audience discussion was encouraged. The manual, visual teaching aids and skill-station equipment was exceptional. At the final wrap-up session there was deafening applause for the instructors.

NEAMC was well attended, despite being the most expensive advanced life support course. Unfortunately, because of its complex logistics, rural and smallurban physicians are unlikely to see it offered in small centres.

I highly recommend this course for emergency physicians who work in moderate- to large-urban emergency departments. Rural physicians from low-volume EDs seemed to find much of the course inappropriate to their setting - where emergency intubation is less common and options more limited. Courses being developed by the Society of Rural Physicians of Canada may be more useful for physicians from smaller rural settings, but instructors of alternative airway courses should consider taking the NEAMC.

James M. Thompson, MD

Associate Professor

Division of Emergency Medicine

Dalhouse University

Charlottetown, PEI

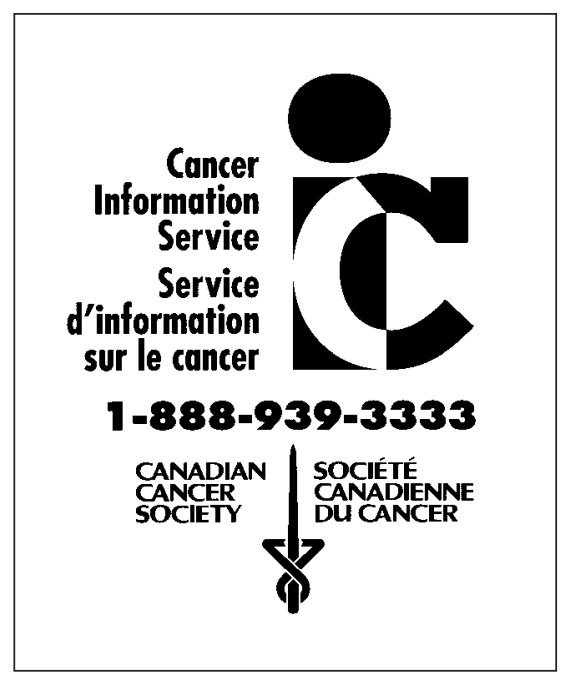

\section{ADVERTISERS' INDEX INDEX DES ANNONCEURS}

Byk Canada Inc.

Panto IV Outside Back Cover

Ethicon Inc.

Dermabond Inside Back Cover

Janssen-Ortho Inc.

Levaquin 4,5

Merrill Lynch Canada

Inside Front Cover

Wyeth-Ayerst Canada Inc.

Cordarone IV 8

PRESCRIBING INFORMATION

Cordarone IV 66, 67, 68

Levaquin 64, 65

Panto IV 63 